\title{
BMJ
}

\section{Tea drinking habits and oesophageal cancer in a high risk area in northern Iran: population based case-control study}

\author{
Farhad Islami, research fellow, ${ }^{1,2,3}$ Akram Pourshams, associate professor, ${ }^{1}$ Dariush Nasrollahzadeh, PhD \\ student, ${ }^{1,4}$ Farin Kamangar, research fellow, ${ }^{5}$ Saman Fahimi, PhD student, ${ }^{1,6}$ Ramin Shakeri, research fellow, ${ }^{1}$ \\ Behnoush Abedi-Ardekani, pathologist, ${ }^{1}$ Shahin Merat, associate professor, ${ }^{1}$ Homayoon Vahedi, associate \\ professor, ${ }^{1}$ Shahryar Semnani, associate professor and director, ${ }^{7}$ Christian C Abnet, investigator, ${ }^{5}$ \\ Paul Brennan, group head, ${ }^{2}$ Henrik Møller, professor and director, ${ }^{3}$ Farrokh Saidi, professor, ${ }^{1}$ \\ Sanford M Dawsey, senior investigator, ${ }^{5}$ Reza Malekzadeh, professor and director, ${ }^{1}$ Paolo Boffetta, group \\ head and cluster coordinator ${ }^{2}$
}

${ }^{1}$ Digestive Disease Research Center, Shariati Hospital, Tehran University of Medical Sciences, 14117 Tehran, Iran

${ }^{2}$ International Agency for Research on Cancer, Lyon, France ${ }^{3}$ King's College London, Thames Cancer Registry, London

${ }^{4}$ Department of Medical Epidemiology and Biostatistics, Karolinska Institute, Stockholm,

\section{Sweden}

${ }^{5}$ Division of Cancer Epidemiology and Genetics, National Cancer Institute, Bethesda, MD, USA

${ }^{6}$ Department of Public Health and Primary Care, Institute of Public Health, University of Cambridge, Cambridge

${ }^{7}$ Golestan Research Center of Gastroenterology and Hepatology, Gorgan University of Medical

Sciences, Gorgan, Iran

Correspondence to: $\mathrm{R}$ Malekzadeh malek@ams.ac.ir or P Boffetta boffetta@iarc.fr

Cite this as: BMJ 2009;338:b929 doi:10.1136/bmj.b929

\section{ABSTRACT}

Objective To investigate the association between tea drinking habits in Golestan province, northern Iran, and risk of oesophageal squamous cell carcinoma.

Design Population based case-control study. In addition, patterns of tea drinking and temperature at which tea was drunk were measured among healthy participants in a cohort study.

Setting Golestan province, northern Iran, an area with a high incidence of oesophageal squamous cell carcinoma. Participants 300 histologically proved cases of oesophageal squamous cell carcinoma and 571 matched neighbourhood controls in the case-control study and 48582 participants in the cohort study.

Main outcome measure Odds ratio of oesophageal squamous cell carcinoma associated with drinking hot tea.

Results Nearly all (98\%) of the cohort participants drank black tea regularly, with a mean volume consumed of over one litre a day. $39.0 \%$ of participants drank their tea at temperatures less than $60^{\circ} \mathrm{C}, 38.9 \%$ at $60-64^{\circ} \mathrm{C}$, and $22.0 \%$ at $65^{\circ} \mathrm{C}$ or higher. A moderate agreement was found between reported tea drinking temperature and actual temperature measurements (weighted $\mathrm{k}$ 0.49). The results of the case-control study showed that compared with drinking lukewarm or warm tea, drinking hot tea (odds ratio $2.07,95 \%$ confidence interval 1.28 to 3.35 ) or very hot tea $(8.16,3.93$ to 16.9$)$ was associated with an increased risk of oesophageal cancer. Likewise, compared with drinking tea four or more minutes after being poured, drinking tea $2-3$ minutes after pouring $(2.49,1.62$ to 3.83$)$ or less than two minutes after pouring $(5.41,2.63$ to 11.1$)$ was associated with a significantly increased risk. A strong agreement was found between responses to the questions on temperature at which tea was drunk and interval from tea being poured to being drunk (weighted $\mathrm{k}$ 0.68).

Conclusion Drinking hot tea, a habit common in Golestan province, was strongly associated with a higher risk of oesophageal cancer.

\section{INTRODUCTION}

Oesophageal squamous cell carcinoma constitutes most of the oesophageal cancers worldwide. ${ }^{12}$ In Europe and America it is mainly caused by tobacco and alcohol use and is more common in men than in women. ${ }^{3}$ However, in Golestan province of Iran, which has one of the highest incidence rates for oesophageal squamous cell carcinoma in the world, ${ }^{4}$ this cancer has relatively unique epidemiological features: smoking and alcohol consumption are not major risk factors ${ }^{56}$ and women are as likely to have a diagnosis of oesophageal cancer as men. ${ }^{7}$ This epidemiological pattern resembles that observed in Linxian, China, another area with a high incidence of oesophageal squamous cell carcinoma. ${ }^{8}$ Earlier studies in Golestan have suggested that low intake of fresh fruits and vegetables, low socioeconomic status, and opium consumption are associated with a higher risk of oesophageal cancer. ${ }^{56}$ In addition, studies have pointed towards the possible role of drinking very hot tea. ${ }^{9}$

An association between drinking hot beverages and risk of oesophageal cancer has been reported in several studies from different parts of the world. ${ }^{310-14}$ In Golestan, tea and water are the only drinks commonly consumed, with comparable average intake. ${ }^{15}$ An ecological study showed that inhabitants of Golestan drank more tea and at a higher temperature than people living in a nearby area with a low incidence of oesophageal cancer. ${ }^{16}$ A case-control study carried out in areas of both low and high incidence in northern Iran in the 1970s showed about a twofold increase in risk of oesophageal cancer among people who drank hot tea, but there was no trend in risk according to quantity of tea consumed. ${ }^{5}$

In contrast with some other risk factors, such as opium consumption, which may affect only a fraction of the general population or may have dissimilar distributions among men and women, tea drinking in Golestan is widespread in both sexes, usually starts at 
an early age, and continues for life. Therefore drinking hot tea could potentially be an important risk factor for oesophageal squamous cell carcinoma in this area. We collected questionnaire data in a case-control study of histologically proved cases of oesophageal squamous cell carcinoma in high incidence areas of Golestan to investigate the association between tea drinking habits and risk of oesophageal cancer. We also measured the usual temperature at which tea was drunk and collected questionnaire data on tea drinking habits in a large scale cohort study in Golestan. We report the results of the case-control study and also tea drinking patterns among 48582 healthy participants within the cohort study.

\section{METHODS}

A detailed description of the design and methods of the case-control study is available elsewhere.$^{6-17}$ Briefly, the study was carried out in the eastern part of Golestan

Table 1 |Characteristics of patients with oesophageal squamous cell carcinoma (cases) and matched controls* in Golestan, northern Iran, 2003-7. Values are numbers (percentages) of participants unless stated otherwise

\begin{tabular}{|c|c|c|c|}
\hline Characteristic & Cases $(n=300)$ & Controls $(n=571)$ & P value \\
\hline Mean (SD) age (years) & $64.5(10.1)$ & $64.3(10.4)$ & 0.81 \\
\hline Men & $150(50.0)$ & $278(48.6)$ & \multirow{2}{*}{0.70} \\
\hline Women & $150(50.0)$ & $293(51.4)$ & \\
\hline \multicolumn{4}{|l|}{ Area of residence: } \\
\hline Urban & $82(27.3)$ & $150(26.3)$ & \multirow{2}{*}{0.77} \\
\hline Rural & $218(72.7)$ & $421(73.7)$ & \\
\hline
\end{tabular}

Duration of residence in rural

areas (years):

\begin{tabular}{|c|c|c|c|}
\hline 0 & $9(3.0)$ & $29(5.1)$ & \multirow{3}{*}{0.36} \\
\hline $1-20$ & $26(8.7)$ & $51(8.9)$ & \\
\hline$>20$ & $264(88.3)$ & $491(86.0)$ & \\
\hline \multicolumn{4}{|l|}{ Ethnicity: } \\
\hline Turkmen & $171(57.0)$ & $312(54.6)$ & \multirow{2}{*}{0.64} \\
\hline Non-Turkmen & $129(43.0)$ & $259(45.4)$ & \\
\hline \multicolumn{4}{|l|}{ Education: } \\
\hline No school & $267(89.0)$ & $474(83.0)$ & \multirow{3}{*}{0.04} \\
\hline Primary school & $25(8.3)$ & $64(11.2)$ & \\
\hline Middle school or higher & $8(2.7)$ & $33(5.8)$ & \\
\hline \multicolumn{4}{|l|}{ Car ownership: } \\
\hline No & $252(84.3)$ & $461(75.6)$ & \multirow{2}{*}{0.003} \\
\hline Yes & $47(15.7)$ & $139(24.4)$ & \\
\hline \multicolumn{4}{|l|}{ Alcohol ever use: } \\
\hline No & $292(97.7)$ & $553(97.4)$ & \multirow{2}{*}{0.86} \\
\hline Yes & $7(2.3)$ & $15(2.6)$ & \\
\hline \multicolumn{4}{|l|}{ Tobacco $\ddagger$ and opium use: } \\
\hline Neither & $166(55.5)$ & $398(69.8)$ & \multirow{4}{*}{0.0002} \\
\hline Tobacco & $43(14.4)$ & $66(11.6)$ & \\
\hline Opium & $30(10.0)$ & $34(6.0)$ & \\
\hline Both & $60(20.1)$ & $72(12.6)$ & \\
\hline
\end{tabular}

As a result of missing data, the number of cases and controls for some variables may be less than 300 and 571 , respectively.

*Although cases and controls were individually matched, percentages of either are not necessarily equal in each category for sex or area of residence as some cases had one matched control and others had two.

$t \mathrm{x}^{2}$ tests for categorical variables ( $\mathrm{x}^{2}$ for trend in variables with more than two categories) and Wilcoxon rank sum test for continuous variables.

$\ddagger$ Any kind of tobacco consumption, including cigarette, pipe, and hookah (water pipe) and chewing nass (a mixture of tobacco, lime, and ash). province, northern Iran. Case participants were recruited between December 2003 and March 2007 at Atrak Clinic, the only gastrointestinal specialty clinic in the study area. Doctors in the study catchment area were asked to refer any patients suspected of having cancers of the upper gastrointestinal tract to Atrak Clinic, where all the patients underwent video oesophagogastroduodenoscopy. Patients with suspicious lesions in the oesophagus during endoscopy were invited to participate in the study; nearly all of those who were invited participated. Fixed biopsy samples were sent to the Tehran University Digestive Disease Research Center, where they were examined by experienced pathologists. Only newly diagnosed patients with histologically confirmed oesophageal cancer were finally included as case participants in the study. Cancer registry data show that nearly $70 \%$ of all incident cases of oesophageal cancer in this area were enrolled in the case-control study (unpublished data). For each case participant we tried to select two population based controls matched to the cases on place of residence, age (SD 2 years), and sex, using data from a family health census that is carried out by the Iranian primary healthcare system and is updated annually. A roster of eligible controls was prepared for each case, from which the controls were selected at random. If the first randomly selected control did not agree to participate, the second person was approached, and so on. Most of the selected controls agreed to participate; of the enrolled controls $77 \%$ were the first randomly selected patients and $11 \%$ the second. In nearly all instances in which selected patients were not enrolled, the reason for not participating was the absence of an eligible control at the time of invitation. Written consent was obtained from all participants.

Using a structured questionnaire trained interviewers collected information on personal characteristics, several other potential confounders of interest, and tea drinking temperature in face to face interviews. The participants were asked whether they drank tea and, if so, whether they usually drank it warm, lukewarm, hot, or very hot. They were also questioned about the interval (in minutes) between tea being poured and drunk. We asked separately about consumption of black and green tea, using a food frequency questionnaire specifically designed for this population ${ }^{18}$; this questionnaire was administered by a trained nutritionist. For this we asked participants about the usual frequency of drinking tea and the volume of the cups usually used. We provided photographs of five types of cups and mugs that are commonly used in the study area. A limited number of staff carried out the interviews and no proxies were used. For cases, the questions referred to the period before symptoms began. Case participants were interviewed on the same day that they underwent diagnostic endoscopy of the upper gastrointestinal tract at Atrak Clinic.

The Golestan Cohort Study is a prospective study that recruited 50045 adults, aged 40-75, from Golestan 
province between January 2004 and June 2008. A total of 16599 inhabitants in the specified age range were selected randomly from Gonbad City, the main urban area in eastern Golestan, by systematic clustering based on the household number. In rural areas, all residents of villages in the study catchment area in the specified age range were invited to participate. Eligible participants were enrolled in the study unless they were unwilling to participate at any stage for any reason, were temporary residents, or had a current or previous diagnosis of an upper gastrointestinal cancer. In urban areas, 10032 participants were enrolled, with participation rates of about $70 \%$ for women and $50 \%$ for men. In rural areas, 40013 participants were enrolled from 326 villages, with participation rates of $84 \%$ for women and $70 \%$ for men.

The same questions for tea temperature were asked as in the case-control study. In addition we measured the temperature of tea drunk by the participants. To achieve this we prepared a fresh cup of tea for each participant and measured the temperature of the tea using a digital thermometer. When the temperature was $75^{\circ} \mathrm{C}$ we asked the participants to sip the tea and say whether that was the temperature at which they usually drank tea. If not, the tea was allowed to cool to $70^{\circ} \mathrm{C}$ and the question was asked again. This procedure was repeated, at $5^{\circ} \mathrm{C}$ intervals, until the temperature at which tea was usually drunk was reached. This method for measuring the temperature of tea showed good reliability when tested in the pilot phase of the cohort study. ${ }^{19}$

\section{Statistical analysis}

The usual interval between tea being poured and drunk was categorised as four or more minutes, 2-3 minutes, and less than two minutes. Within the case-control study the amount of black tea consumed each day (millilitres) was categorised into fifths. For green tea, however, because only a small number of participants drank this kind of tea, we present only the frequency of consumption. Data on tea temperature were available for over $99 \%$ of cases and of controls. The amount of tea, however, was available for $89 \%$ of the cases and $67 \%$ of the controls. We excluded participants with missing data on a variable from the corresponding analysis. Conditional logistic regression was used to calculate odds ratios and corresponding 95\% confidence intervals. By design, case and control participants were matched for age, sex, and place of residence. We used logistic regression models to adjust for potential confounders, including ethnicity, daily vegetable intake, alcohol consumption, tobacco or opium use, duration of residence in rural areas, education level, and car ownership, as indicators of socioeconomic status, and other tea drinking variables. $\mathrm{P}$ values for trend were obtained from adjusted

Table 2 | Distribution of usual tea drinking habits and corresponding odds ratios (95\% Cls) among 300 cases with oesophageal squamous cell carcinoma and 571 matched controls, in Golestan, northern Iran, 2003-7. Values are numbers (percentages) of participants unless stated otherwise

\begin{tabular}{|c|c|c|c|c|c|}
\hline Variables & $\begin{array}{l}\text { Cases } \\
(n=300)\end{array}$ & $\begin{array}{l}\text { Controls } \\
(n=571)\end{array}$ & Crude odds ratio $(95 \% \mathrm{Cl})$ & Adjusted odds ratio* $(95 \% \mathrm{Cl})$ & $\begin{array}{l}\text { P value for } \\
\text { trend } \dagger\end{array}$ \\
\hline \multicolumn{6}{|l|}{ Tea temperature: } \\
\hline Hot & $108(36.2)$ & $155(27.3)$ & 2.14 (1.52 to 3.01$)$ & 2.07 (1.28 to 3.35$)$ & \multirow[t]{2}{*}{$<0.001$} \\
\hline Very hot & $63(21.1)$ & $19(3.3)$ & $9.33(5.26$ to 16.56$)$ & $8.16(3.93$ to 16.91$)$ & \\
\hline
\end{tabular}

Interval between tea being poured

and drunk (minutes):

\begin{tabular}{|c|c|c|c|c|c|}
\hline$\geq 4$ & $132(44.3)$ & $394(69.5)$ & 1.00 & 1.00 & \multirow{3}{*}{$<0.001$} \\
\hline $2-3$ & $112(37.6)$ & $138(24.3)$ & 2.32 (1.68 to 3.23$)$ & 2.49 (1.62 to 3.83$)$ & \\
\hline$<2$ & $54(18.1)$ & $35(6.2)$ & $4.03(2.50$ to 6.49$)$ & 5.41 (2.63 to 11.14$)$ & \\
\hline
\end{tabular}

Amount of black tea consumed

(ml/day):

\begin{tabular}{lllll}
\hline $0-675$ & $48(18.0)$ & $81(21.0)$ & 1.00 & 1.00 \\
\hline $676-920$ & $40(15.0)$ & $75(19.5)$ & $0.85(0.46$ to 1.58$)$ & $0.91(0.43$ to 1.91$)$ \\
\hline $921-1215$ & $37(13.9)$ & $86(22.3)$ & $0.68(0.38$ to 1.23$)$ & $0.68(0.34$ to 1.37$)$ \\
\hline $1216-1725$ & $65(24.3)$ & $70(18.2)$ & $1.57(0.89$ to 2.75$)$ & $1.46(0.75$ to 2.86$)$ \\
\hline$\geq 1726$ & $77(28.8)$ & $73(19.0)$ & $1.86(1.07$ to 3.23$)$ & 1.83 (0.93 to 3.59) \\
\hline
\end{tabular}

Frequency of green tea

consumption:

\begin{tabular}{lcccc} 
Never, sweekly & $249(93.6)$ & $356(92.2)$ & 1.00 & 1.00 \\
\cline { 1 - 4 } Daily, weekly & $17(6.4)$ & $30(7.8)$ & $0.65(0.32$ to 1.31$)$ & $0.89(0.38$ to 2.09$)$
\end{tabular}

Because of missing data and one participant who did not drink tea, number of cases and controls for some variables may be less than 300 and 571 , respectively.

*Adjusted for ethnicity (non-Turkmen or Turkmen), daily vegetable intake (logarithmic scale), alcohol consumption (never or ever), tobacco or opium ever use (none, only tobacco, only opium, or both), duration of residence in rural areas (0,1-20 years, or >20 years), education level (no school, primary school, or middle school or higher), car ownership (no or yes), and variables listed in table, excluding interval variable; interval variable was not adjusted for tea temperature.

†P values come from adjusted conditional logistic regression models in which consecutive integers were assigned to consecutive categories of each variable. 
Table 3 - Comparison of questionnaire data on tea temperature among 300 cases with oesophageal squamous cell carcinoma and 571 matched controls, in Golestan, northern Iran, 2003-7

\begin{tabular}{|c|c|c|c|c|c|}
\hline \multirow[b]{2}{*}{$\begin{array}{l}\text { Interval } \\
\text { (minutes)* }\end{array}$} & \multicolumn{3}{|c|}{ Tea temperature } & \multirow[b]{2}{*}{$\begin{array}{c}\text { Weighted K } \\
\text { statistics (SE) }\end{array}$} & \multirow[b]{2}{*}{$\begin{array}{c}\text { Correlation coefficient } † \\
\text { (P value) }\end{array}$} \\
\hline & $\begin{array}{l}\text { Warm or } \\
\text { lukewarm }\end{array}$ & Hot & Very hot & & \\
\hline$\geq 4$ & 454 & 65 & 7 & \multirow{3}{*}{$0.68(0.03)$} & \multirow{3}{*}{$0.69(<0.001)$} \\
\hline $2-3$ & 57 & 163 & 30 & & \\
\hline$<2$ & 8 & 35 & 45 & & \\
\hline
\end{tabular}

Because of missing data and one participant who did not drink tea, numbers add up to 864 rather than 871 . *Interval between tea being poured and drunk.

†Spearman's rank correlation coefficient.

conditional logistic regression models by assigning consecutive numbers to categories within each categorical variable. We tested the agreement between tea temperature categories and the interval between tea being poured and drunk by weighted $\kappa$ statistics and Spearman's rank correlation coefficients.

Less than $3 \%$ of the cohort participants had one or more missing values in tea drinking variables. These participants were excluded from the current analyses. We calculated means and standard deviations for daily intake of black and green tea among the cohort participants and the percentage of participants who drank these two kinds of tea daily, weekly, or less. In addition, we examined the validity of the questionnaire data on tea temperature within the cohort study. For this we categorised tea temperature measurements as less than $65^{\circ} \mathrm{C}, 65-69^{\circ} \mathrm{C}$, and $70^{\circ} \mathrm{C}$ or more, because their distribution was close to that of the categorical variable used in the questionnaire. We then compared them with the questionnaire data, using weighted $\kappa$ statistics and Spearman's rank correlation coefficients.

The methods of sample size calculation for both studies are presented in the web extra. Throughout the analyses we considered two sided $\mathrm{P}$ values $<0.05$ as significant. All statistical analyses were done using Stata version 10.0 software.

\section{RESULTS}

\section{Case-control study}

A total of 300 cases and 571 controls were recruited into the study. All cases had at least one matched control. The personal characteristics of the cases and controls were similar (table 1).

Only one participant did not drink tea. Tea temperature was significantly associated with risk of oesophageal squamous cell carcinoma (table 2). Compared with drinking warm or lukewarm tea, drinking hot tea (odds ratio $2.07,95 \%$ confidence interval 1.28 to $3.35)$ or very hot tea $(8.16,3.93$ to 16.91$)$ was associated with an increased risk of oesophageal cancer ( $\mathrm{P}$ for trend $<0.001)$. The risk associated with drinking hot tea did not vary by education level or several other personal variables (see web extra table). The interval between tea being poured and drunk was inversely associated with risk of oesophageal cancer (table 2). Compared with an interval of four or more minutes, intervals of $2-3$ minutes (odds ratio $2.49,95 \%$ confidence interval 1.62 to 3.83 ) and less than two minutes $(5.41,2.63$ to 11.14$)$ were associated with an increased risk of oesophageal cancer ( $\mathrm{P}$ for trend $<0.001)$. The weighted $\kappa$ statistic and Spearman's rank correlation coefficient for agreement between these two variables were 0.68 and 0.69 , respectively (table 3 ). A similar agreement was observed within the case and control groups and among men and women separately (data not shown). Information on amount of tea drunk was available for only 267 cases and 385 controls. No clear pattern of association was found between the amount of black tea consumed and risk of cancer in crude or multivariate analyses, but the trend test was statistically

Table 4 | Usual mean daily amount and frequency of tea drinking among 48582 participants in Golestan Cohort Study, Golestan, northern Iran, $2004-8$. Values are percentages of participants unless stated otherwise

\begin{tabular}{|c|c|c|c|c|c|c|c|c|c|}
\hline \multirow[b]{3}{*}{ Characteristics } & \multirow[b]{3}{*}{ Total No } & \multicolumn{4}{|c|}{ Black tea } & \multicolumn{4}{|c|}{ Green tea } \\
\hline & & \multirow[b]{2}{*}{$\begin{array}{c}\text { Mean (SD) } \\
\text { volume (ml/day) }\end{array}$} & \multicolumn{3}{|c|}{ Frequency of consumption } & \multirow[b]{2}{*}{$\begin{array}{c}\text { Mean (SD) } \\
\text { volume (ml/day) }\end{array}$} & \multicolumn{3}{|c|}{ Frequency of consumption } \\
\hline & & & Daily & 1-6 days a week & $\begin{array}{l}\text { Never, } \\
\text { «weekly }\end{array}$ & & Daily & $\begin{array}{l}\text { 1-6 days } \\
\text { weekly }\end{array}$ & Never, «weekly \\
\hline Total & 48582 & $1179(761)$ & 96.8 & 0.6 & 2.6 & $48(228)$ & 5.8 & 4.7 & 89.5 \\
\hline Men & 20649 & $1306(869)$ & 97.3 & 0.5 & 2.2 & $41(218)$ & 4.8 & 4.2 & 91.0 \\
\hline Women & 27933 & $1085(655)$ & 96.5 & 0.6 & 2.9 & $52(235)$ & 6.5 & 5.2 & 88.3 \\
\hline \multicolumn{10}{|l|}{ Area of residence: } \\
\hline Urban & 9949 & $1182(823)$ & 98.0 & 0.7 & 1.3 & 37 (179) & 6.0 & 7.0 & 87.0 \\
\hline Rural & 38633 & $1178(745)$ & 96.5 & 0.5 & 3.0 & $50(239)$ & 5.7 & 4.2 & 90.1 \\
\hline \multicolumn{10}{|l|}{ Ethnicity: } \\
\hline Non-Turkmen & 12610 & $1186(749)$ & 99.0 & 0.3 & 0.7 & $6(77)$ & 0.9 & 1.0 & 98.1 \\
\hline Turkmen & 35972 & $1176(765)$ & 96.1 & 0.6 & 3.3 & $62(260)$ & 7.5 & 6.1 & 86.4 \\
\hline \multicolumn{10}{|l|}{ Formal education: } \\
\hline None & 33990 & $1158(720)$ & 96.4 & 0.5 & 3.1 & $53(245)$ & 6.2 & 4.7 & 89.1 \\
\hline Primary school & 8253 & $1225(813)$ & 97.9 & 0.5 & 1.6 & 37 (195) & 4.6 & 4.5 & 90.9 \\
\hline Middle school & 2205 & $1239(884)$ & 97.6 & 0.8 & 1.5 & 34 (178) & 4.4 & 4.5 & 91.1 \\
\hline High school & 3095 & $1246(913)$ & 98.0 & 0.6 & 1.4 & $31(150)$ & 4.8 & 5.6 & 89.6 \\
\hline College or university & 1039 & $1151(830)$ & 98.0 & 1.0 & 1.0 & $46(188)$ & 7.4 & 7.4 & 85.2 \\
\hline
\end{tabular}


Table 5|Usual tea drinking temperature among 48582 participants in Golestan Cohort Study, Golestan, northern Iran, 2004-8. Values are percentages of participants unless stated otherwise

\begin{tabular}{|c|c|c|c|c|c|c|}
\hline \multirow[b]{2}{*}{ Characteristics } & \multirow[b]{2}{*}{ Total No } & \multicolumn{5}{|c|}{ Temperature $\left({ }^{\circ} \mathrm{C}\right)$} \\
\hline & & Never & $<60$ & $60-64$ & $65-69$ & $\geq 70$ \\
\hline Total & 48582 & 0.1 & 39.0 & 38.9 & 16.6 & 5.4 \\
\hline Men & 20649 & 0.2 & 31.6 & 40.0 & 20.3 & 7.9 \\
\hline Women & 27933 & 0.1 & 44.5 & 38.1 & 13.7 & 3.6 \\
\hline \multicolumn{7}{|l|}{ Area of residence: } \\
\hline Urban & 9949 & 0.1 & 42.2 & 36.6 & 15.7 & 5.4 \\
\hline Rural & 38633 & 0.1 & 38.2 & 39.5 & 16.8 & 5.5 \\
\hline \multicolumn{7}{|l|}{ Ethnicity: } \\
\hline Non-Turkmen & 12610 & 0.3 & 37.2 & 40.6 & 16.7 & 5.2 \\
\hline Turkmen & 35972 & 0.1 & 39.6 & 38.3 & 16.5 & 5.5 \\
\hline \multicolumn{7}{|l|}{ Formal education: } \\
\hline None & 33990 & 0.1 & 39.4 & 38.8 & 16.5 & 5.2 \\
\hline Primary school & 8253 & 0.1 & 37.4 & 39.7 & 16.9 & 5.9 \\
\hline Middle school & 2205 & 0.4 & 35.7 & 39.9 & 16.8 & 7.2 \\
\hline High school & 3095 & 0.2 & 38.7 & 38.1 & 17.1 & 5.9 \\
\hline College or university & 1039 & 0.2 & 46.2 & 33.5 & 14.5 & 5.6 \\
\hline
\end{tabular}

significant (P value for trend 0.03). There was no statistically significant association between frequency of green tea consumption and risk of cancer.

\section{Cohort study}

Data on tea drinking variables were available for 48582 cohort participants. Almost all $(96.8 \%)$ of the participants drank black tea every day (47043 participants), with a mean amount of $1179 \mathrm{ml}$ (SD 761) a day. Only 2802 participants (5.8\% of all participants) drank green tea every day; most of them were of Turkmen ethnicity. The mean amount of green tea consumption was $48 \mathrm{ml}$ (SD 228) a day (table 4). Overall, 18947 $(39.0 \%)$ participants drank their tea at temperatures less than $60^{\circ} \mathrm{C}, 18889(38.9 \%)$ at $60-64^{\circ} \mathrm{C}$, and 10688 $(22.0 \%)$ at $65^{\circ} \mathrm{C}$ or higher (table 5).

The weighted $\kappa$ statistic and Spearman's rank correlation coefficient for agreement between reported tea drinking temperature and actual temperature measurements were 0.49 and 0.46 , respectively (table 6 ). The corresponding values for agreement between actual measurements and the interval between tea being poured and drunk were 0.39 and 0.32 , respectively.

\section{DISCUSSION}

Our study found that almost everyone in Golestan Province drinks tea. They drink large amounts of black tea every day, but drinking green tea is not common. We found a strong increase in the risk of oesophageal squamous cell carcinoma associated with drinking hot or very hot tea but not with the amount of tea consumed, which is consistent with the previous literature. ${ }^{3}$

Compared with rats that received only carcinogenic $\mathrm{N}$-nitroso compounds or hot water, the mean number of benign and malignant oesophageal tumours significantly increased in rats that received both $\mathrm{N}$-nitroso compounds and hot water. ${ }^{2021}$ In one of these studies, ${ }^{21}$ in which hot water was administered by installation in the upper section of the oesophagus, more tumours were observed as the temperature increased, especially at $65^{\circ} \mathrm{C}$ and above. At a temperature of $70^{\circ} \mathrm{C}$ the number and size of oesophageal papillomas increased rapidly. ${ }^{21} \mathrm{~A}$ few studies have investigated the effect of hot beverages on intraoesophageal temperature in humans. ${ }^{2223}$ One study showed that after drinking beverages with temperatures up to $65^{\circ} \mathrm{C}$, distal oesophageal temperature increased to as high as $53^{\circ} \mathrm{C} .{ }^{23}$ The volume swallowed in each sip was more important than the temperature of the beverage in determining intraoesophageal temperature. ${ }^{23}$ In our study we asked the participants if they sipped or gulped their tea, but we did not analyse these data because few participants gulped their tea. In addition, we did not find a good way to validate the answers to this question. The volume swallowed in each sip may differ from person to person, and a given volume may be divided in two or more quick swallows.

\section{Possible mechanistic pathways}

The mechanism by which thermal injury can cause oesophageal cancer is not clear but both direct and indirect effects have been suggested. Some authors have proposed that inflammatory processes associated with chronic irritation of the oesophageal mucosa by local hyperthermia might stimulate the endogenous formation of reactive nitrogen species, such as nitric oxide, and subsequently, $\mathrm{N}$-nitroso compounds. ${ }^{24}$ Consistent with this idea, higher rates of transitions of somatic $\mathrm{G}$ to $\mathrm{A}$ in $\mathrm{CpG}$ dinucleotides of the TP53 gene have been reported in samples of oesophageal tumour from areas in which drinking hot beverages is considered an important risk factor for oesophageal cancer, ${ }^{25-28}$ and an association between these mutations and nitric oxide synthase activity has been reported in colorectal cancers in humans. ${ }^{29}$ Thermal injury can also impair the barrier function of the oesophageal epithelium, which may increase the risk of damage 
from exposure to intraluminal carcinogens $\mathrm{s}^{202130}$ such as polycyclic aromatic hydrocarbons or the compounds present in opium dross. The population of Golestan is highly exposed to polycyclic aromatic hydrocarbons, most probably through diet. ${ }^{3132}$ Threshold temperatures have been suggested for the effect of hot beverages on the epithelial barrier of the oesophagus in rabbits (intraluminal temperature of $49^{\circ}$ $\mathrm{C}$ for epithelium permeability and of $60^{\circ} \mathrm{C}$ for active ion transport). Once the threshold temperature is reached, the barrier function could be impaired rapidly and with short exposure times. ${ }^{30}$ Whatever the mechanism by which thermal injury increases the risk of oesophageal cancer, this risk can be augmented by other risk factors, such as low intake of fresh fruits and vegetables, which can impair DNA repair. ${ }^{33}$

Both green and black teas have shown cancer prevention activity in animal models, which may be attributable to flavonoids and other beneficial compounds $^{34-36}$; however, such activity has not been convincingly shown in humans. ${ }^{3738}$ After adjustment for tea temperature and other factors we did not find a clear pattern of association between the amount of tea consumed and the risk of oesophageal cancer. Although the $\mathrm{P}$ value for trend for this association was statistically significant, the risk decreased from the first to the third fifths and then increased, so there was no consistent pattern. In contrast with tea, which is possibly carcinogenic only if it is drunk at high temperatures, ${ }^{3}$ drinking maté, a herbal infusion consumed in certain areas of South America, may increase the risk of oesophageal cancer even at low temperatures. ${ }^{12} 39$ This increased risk may be due to carcinogens that are produced during the processing of the herbal leaves, such as polycyclic aromatic hydrocarbons, or to other compounds present in the unprocessed leaves. $^{4041}$

\section{Comparison with other studies}

The results of the cohort study showed that most inhabitants of Golestan drink their tea at temperatures higher than $60^{\circ} \mathrm{C}$ and in quantities greater than one litre a day. These patterns make the Golestan population particularly vulnerable to the possible carcinogenic effects of drinking hot tea. Several previous studies have assessed temperature preferences for beverages, and those from the United Kingdom have reported an average temperature preference of $56-60^{\circ} \mathrm{C}$ among healthy populations..$^{162242-45}$ One study reported a significantly higher tea drinking temperature among seven participants with oesophageal disorders (mean $62^{\circ} \mathrm{C}$, range $53-73^{\circ} \mathrm{C}$ ) than among 50 controls (mean $56^{\circ} \mathrm{C}$, range $47.5-65^{\circ} \mathrm{C}$, $\mathrm{P}<0.001) .{ }^{43}$ Another study reported a mean temperature of $69.5^{\circ} \mathrm{C}\left(\mathrm{SD} 6.5^{\circ} \mathrm{C}\right)$ for drinking maté among 1388 inhabitants in southern Brazil, a moderate to high incidence area for oesophageal squamous cell carcinoma. $^{44}$

The association between drinking hot beverages and risk of oesophageal cancer suggests that thermal injury could be a cause of other cancers of the upper aerodigestive epithelial; however, this hypothesis has been investigated in only a few epidemiological studies. For hot tea drinking, the evidence is too limited to draw any conclusions. ${ }^{46-48}$ All of the six studies that investigated maté drinking and cancer of the mouth, pharynx, and larynx showed an association with hot maté intake, which was statistically significant in four studies. ${ }^{48}$ Potential carcinogenic effects of hot beverages on other parts of the upper aerodigestive tract warrant further investigations.

\section{Strengths and limitations of the study}

To our knowledge the Golestan Cohort Study is the largest epidemiological study in which tea drinking temperature has been measured. The measurement method was validated in the pilot phase of this study ${ }^{19}$ and all measurements were done by trained staff. The strengths of our case-control study include histological verification of all cases of oesophageal squamous cell carcinoma, administration of a structured questionnaire by well trained interviewers, and adjustment for potential confounders. Furthermore, with no or minimal confounding from alcohol or tobacco use in Golestan, other risk factors for oesophageal cancer can be better studied there. As in all casecontrol studies, however, data on the amount and temperature of consumed tea can be subject to information

Table 6|Agreement between tea temperature variables among 48582 participants in Golestan Cohort Study, Golestan, northern Iran, 2004-8

\begin{tabular}{|c|c|c|c|c|c|}
\hline \multirow[b]{2}{*}{ Descriptive variables } & \multicolumn{3}{|c|}{ Measured temperatures } & \multirow[b]{2}{*}{ Weighted k statistic (SE) } & \multirow{2}{*}{$\begin{array}{l}\text { Spearman's rank } \\
\text { correlation } \\
\text { coefficient ( } P \text { value) }\end{array}$} \\
\hline & $<65^{\circ} \mathrm{C}$ & $65-69^{\circ} \mathrm{C}$ & $\geq 70^{\circ} \mathrm{C}$ & & \\
\hline \multicolumn{6}{|l|}{ Tea temperature: } \\
\hline Warm or lukewarm & 32414 & 3749 & 467 & \multirow{3}{*}{$0.49(0.005)$} & \multirow{3}{*}{$0.46(<0.001)$} \\
\hline Hot & 5385 & 4246 & 1757 & & \\
\hline Very hot & 37 & 48 & 421 & & \\
\hline \multicolumn{6}{|c|}{$\begin{array}{l}\text { Interval between tea being poured } \\
\text { and drunk (minutes) }\end{array}$} \\
\hline$\geq 4$ & 30259 & 4678 & 675 & \multirow{3}{*}{$0.39(0.005)$} & \multirow{3}{*}{$0.32(<0.001)$} \\
\hline $2-3$ & 6836 & 2691 & 859 & & \\
\hline$<2$ & 741 & 674 & 1111 & & \\
\hline
\end{tabular}


bias. We found good agreement between questions on the temperature that tea was drunk and the interval between tea being poured and drunk, but responses to both questions could have been biased. The validation study in the cohort was carried out among healthy people, so the observed acceptable validity may not be applicable to case participants. Studies in the Caspian littoral in the 1970 s suggested that drinking hot beverages may be a possible risk factor for oesophageal squamous cell carcinoma, so the hypothesis might be familiar to the interviewers and people of the study area; however, we are not aware of any public educational programme in this regard. We tried to minimise the risk of information bias by not discussing the study hypotheses with the interviewers. The questionnaires were fairly extensive, studying multiple hypotheses, which reduced the possibility of interviewers' focusing on a certain hypothesis. Also, we did not observe any evidence of inflated results for other known risk factors for oesophageal cancer, such as tobacco smoking or alcohol consumption, which further suggests that severe information bias is not highly likely. ${ }^{6}$ Case participants with no formal education might be less likely to be aware of the study hypotheses, so they might be less prone to recall bias. In our sensitivity analyses we found no substantial difference in the risk associated with hot tea drinking between participants with and without formal education, or between urban and rural areas. Another problem with a case-control design is selection bias. Since ascertainment of cases and controls in our study was high, selection bias may only explain our findings if the small proportion of non-participating cases were overwhelmingly drinkers of "cold tea" or, conversely, the non-participating controls were overwhelmingly drinkers of "hot tea." None of the scenarios are likely. In our study the amount of missing data on the variable for amount of tea drinking varied between cases and controls, which was due to a logistical issue rather than bias. The questions on amount of tea drunk came from a nutritional

\section{WHAT IS ALREADY KNOWN ON THIS TOPIC}

Heavy alcohol and tobacco use are major risk factors for oesophageal squamous cell carcinoma, a disease more common in men than women

In some areas with a high incidence of oesophageal cancer, alcohol and tobacco use are not prominent risk factors, and women are as likely to develop oesophageal cancer as men

Common risk factors among both sexes may have a role in the carcinogenesis of oesophageal cancer; drinking hot beverages is a suggested risk factor

\section{WHAT THIS STUDY ADDS}

The risk of oesophageal cancer was noticeably increased in adults in Golestan Province, northern Iran, who drank tea hot

Drinking hot beverages is common and may account for a substantial number of cases of oesophageal squamous cell carcinoma, especially in areas with a high incidence questionnaire that was administered by a nutritionist. On some days no nutritionist was available to accompany the control selection team and therefore this variable has some missing data. Since we used conditional logistic regression models, in which each case is compared with their matched controls, the missing values are not expected to differentially distort our findings even if there are some differences in the personal characteristics of participants with or without missing values. Despite the presence of the missing data, we report the results of amount of tea consumed in relation to the risk of oesophageal squamous cell carcinoma because even after excluding the participants with missing values, our study is still one of the largest that have reported on this association. Overall, we believe that the strong association between drinking hot tea and risk of oesophageal cancer found in this study is unlikely to be completely due to bias, considering its agreement with the previous literature and our efforts to collect accurate and valid data. Nonetheless, we acknowledge that the nature and strength of the association needs to be established in prospective studies.

\section{Conclusions and policy implications}

Our results showed a noticeable increase in risk of oesophageal squamous cell carcinoma associated with drinking tea hot. A large proportion of Golestan inhabitants drink hot tea, so this habit may account for a substantial proportion of the cases of oesophageal cancer in this population. Informing the population about the hazards of drinking hot tea may be helpful in reducing the incidence of oesophageal cancer in Golestan and in other high risk populations where similar habits are prevalent.

We thank the staff of the Atrak Clinic, including Karim Aghcheli, Noushin Taghavi, Haji-Amin Marjani, Rabaeh Rajabzadeh, Monireh Badakhshan, Bita Mohammadi, Halimeh Eskandarnejhad, Safora Kor, Soleiman Kasalkheh, and Ashor Yolmeh; Noorli Radgohar, Abdolazim Khozeini, Rahmat Ghaziani, Mohammad Hasan Brazandeh, Abdolhakim Ebadati, Naser Keramat, and Ahmad Nosrati for their valuable help; the local health networks and health workers (Behvarzes) in the study area for their assistance in recruitment of controls; the Iranian Social Security Organization for their local support; and the Golestan Cohort Study Center staff for their dedicated work.

Contributors: FI, AP, DN, FK, SF, RS, BA-A, SM, HV, CCA, PBren, FS, SMD, RM, and PBoff designed and implemented the study. FI, AP, DN, SF, RS, $B A-A, S M, H V, S S, F S$, and RM acquired the data. FI analysed the data. FI, PBoff, FK, SD, HM, and RM interpreted the data. FI, FK, and PBoff drafted the manuscript. All authors reviewed the manuscript and approved the final version to be published.

Funding: This study was supported by the Digestive Disease Research Center of Tehran University of Medical Sciences (grant No 82-603), by an intramural programme of the National Cancer Institute, National Institutes of Health, and by the International Agency for Research on Cancer. The funding sources had no role in the design, conduct, statistical analysis and interpretation of results, or writing of the manuscript.

Competing interests: None declared

Ethical approval: The case-control study was reviewed and approved by the institutional review boards of the Digestive Disease Research Center (DDRC) of Tehran University of Medical Sciences and the US National

Cancer Institute. Both cases and controls gave written informed consent for the interview. The conduct of Golestan Cohort Study was reviewed and approved by the institutional review boards of DDRC, the International Agency for Research on Cancer, and the US National Cancer Institute. 
1 Parkin DM, Bray F, Ferlay J, Pisani P. Global cancer statistics, 2002. CA Cancer/ Clin 2005;55:74-108.

2 Kamangar F, Dores GM, Anderson WF. Patterns of cancer incidence, mortality, and prevalence across five continents: defining priorities to reduce cancer disparities in different geographic regions of the world. . Clin Oncol 2006;24:2137-50.

3 Blot WJ, McLaughlin JK, Fraumeni JF. Esophageal cancer. In: Schottenfeld D, Fraumeni JF, eds. Cancer epidemiology and prevention. New York: Oxford University Press, 2006.

4 Mahboubi E, Kmet J, Cook PI, Day NE, Ghadirian P, Salmasizadeh S. Oesophageal cancer studies in the Caspian Littoral of Iran: the Caspian cancer registry. Br J Cancer 1973;28:197-214.

5 Cook-Mozaffari PJ, Azordegan F, Day NE, Ressicaud A, Sabai C, Aramesh B. Oesophageal cancer studies in the Caspian Littoral of Iran: results of a case-control study. Br J Cancer 1979;39:293-309.

6 Nasrollahzadeh D, Kamangar F, Aghcheli K, Sotoudeh M, Islami F, Abnet CC, et al. Opium, tobacco, and alcohol use in relation to oesophageal squamous cell carcinoma in a high-risk area of Iran. $\mathrm{Br}$. Cancer 2008;98:1857-63.

7 Islami F, Kamangar F, Aghcheli K, Fahimi S, Semnani S, Taghavi N, et al. Epidemiologic features of upper gastrointestinal tract cancers in Northeastern Iran. Br J Cancer 2004;90:1402-6.

8 Tran GD, Sun XD, Abnet CC, Fan JH, Dawsey SM, Dong ZW, et al. Prospective study of risk factors for esophageal and gastric cancers in the Linxian general population trial cohort in China. Int / Cancer 2005;113:456-63.

9 Kamangar F, Malekzadeh R, Dawsey SM, Saidi F. Esophageal cance in northeastern Iran: a review. Arch Iran Med 2007:10:70-82.

10 De Jong UW, Breslow N, Hong JG, Sridharan M, Shanmugaratnam K. Aetiological factors in oesophageal cancer in Singapore Chinese. Int Cancer 1974;13:291-303.

11 Launoy G, Milan C, Day NE, Faivre J, Pienkowski P, Gignoux M. Oesophageal cancer in France: potential importance of hot alcoholic drinks. Int / Cancer 1997;71:917-23.

12 Castellsague X, Munoz N, De Stefani E, Victora CG, Castelletto R, Rolon PA. Influence of mate drinking, hot beverages and diet on esophageal cancer risk in South America. Int J Cancer 2000;88:658-64.

13 Sharp L, Chilvers CE, Cheng KK, McKinney PA, Logan RF, Cook-Mozaffari P, et al. Risk factors for squamous cell carcinoma of the oesophagus in women: a case-control study. Br J Cancer 2001;85:1667-70.

14 Phukan RK, Chetia CK, Ali MS, Mahanta J. Role of dietary habits in the development of esophageal cancer in Assam, the north-eastern region of India. Nutr Cancer 2001;39:204-9.

15 Joint Iran-IARC group. Esophageal cancer studies in the Caspian littoral of Iran: results of population studies - a prodrome. Joint IranInternational Agency for Research on Cancer Study Group. J Nat Cancer Inst 1977;59:1127-38.

16 Ghadirian P. Thermal irritation and esophageal cancer in northern Iran. Cancer 1987;60:1909-14.

17 Abnet CC, Kamangar F, Islami F, Nasrollahzadeh D, Brennan P, Aghcheli K, et al. Tooth loss and lack of regular oral hygiene are associated with higher risk of esophageal squamous cell carcinoma. Cancer Epidemiol Biomarkers Prev 2008;17:3062-8.

18 Malekshah AF, Kimiagar M, Saadatian-Elahi M, Pourshams A, Nouraie M, Goglani G, et al. Validity and reliability of a new food frequency questionnaire compared to $24 \mathrm{~h}$ recalls and biochemical measurements: pilot phase of Golestan cohort study of esophageal cancer. Eur / Clin Nutr 2006;60:971-7.

19 Pourshams A, Saadatian-Elahi M, Nouraie M, Malekshah AF, Rakhshani N, Salahi R, et al. Golestan cohort study of oesophageal cancer: feasibility and first results. Br/ Cancer 2005;92:176-81.

20 Yioris N, Ivankovic S, Lehnert T. Effect of thermal injury and oral administration of N-methyl-N'-Nitro-N-nitrosoguanidine on the development of esophageal tumors in Wistar rats. Oncology 1984;41:36-8

21 Li ZG, Shimada Y, Sato F, Maeda M, Itami A, Kaganoi J, et al. Promotion effects of hot water on $\mathrm{N}$-nitrosomethylbenzylamineinduced esophageal tumorigenesis in F344 rats. Oncol Rep 2003;10:421-6.

22 Dsvis RE, Ivy AC. Thermal irritation in gastric disease. Cancer 1949;2:138-43.

23 De Jong UW, Day NE, Mounier-Kuhn PL, Haguenauer JP. The relationship between the ingestion of hot coffee and intraoesophageal temperature. Gut 1972;13:24-30.

24 Mirvish SS. Role of $\mathrm{N}$-nitroso compounds (NOC) and N-nitrosation in etiology of gastric, esophageal, nasopharyngeal and bladder cancer and contribution to cancer of known exposures to NOC. Cancer Lett 1995;93:17-48.
25 Putz A, Hartmann AA, Fontes PR, Alexandre CO, Silveira DA, Klug S, et al. TP53 mutation pattern of esophageal squamous cell carcinomas in a high risk area (southern Brazil): role of life style factors. Int / Cancer 2002;98:99-105.

26 Breton J, Sichel F, Abbas A, Marnay J, Arsene D, Lechevrel M. Simultaneous use of DGGE and DHPLC to screen TP53 mutations in cancers of the esophagus and cardia from a European high incidence area (lower Normandy, France). Mutagenesis 2003;18:299-306.

27 Biramijamal F, Allameh A, Mirbod P, Groene HJ, Koomagi R, Hollstein M. Unusual profile and high prevalence of $p 53$ mutations in esophageal squamous cell carcinomas from northern Iran. Cancer Res 2001;61:3119-23.

28 Sepehr A, Taniere P, Martel-Planche G, Zia'ee AA, Rastgar-Jazii F, Yazdanbod M, et al. Distinct pattern of TP53 mutations in squamous cell carcinoma of the esophagus in Iran. Oncogene 2001;20:7368-74

29 Ambs S, Bennett WP, Merriam WG, Ogunfusika MO, Oser SM, Harrington AM, et al. Relationship between p 53 mutations and inducible nitric oxide synthase expression in human colorectal cancer. I Natl Cancer Inst 1999;91:86-8.

30 Tobey NA, Sikka D, Marten E, Caymaz-Bor C, Hosseini SS, Orlando RC. Effect of heat stress on rabbit esophageal epithelium. Am J Physiol 1999;276:G1322-30.

31 Kamangar F, Strickland PT, Pourshams A, Malekzadeh R, Boffetta P, Roth MJ, et al. High exposure to polycyclic aromatic hydrocarbons may contribute to high risk of esophageal cancer in northeastern Iran. Anticancer Res 2005;25:425-8.

32 Hakami R, Mohtadinia J, Etemadi A, Kamangar F, Nemati M, Pourshams A, et al. Dietary intake of benzo(a)pyrene and risk of esophageal cancer in North of Iran. Nutr Cancer 2008;60:216-21.

33 Ames BN, Wakimoto P. Are vitamin and mineral deficiencies a major cancer risk? Nat Rev Cancer 2002;2:694-704.

34 Wang ZY, Wang LD, Lee MJ, Ho CT, Huang MT, Conney AH, et al. Inhibition of N-nitrosomethylbenzylamine-induced esophageal tumorigenesis in rats by green and black tea. Carcinogenesis 1995;16:2143-8.

35 Boone CW, Stoner GD, Bacus JV, Kagan V, Morse MA, Kelloff GJ, et al. Chemoprevention with theaflavins of rat esophageal intraepithelial neoplasia quantitatively monitored by image tile analysis. Cancer Epidemiol Biomarkers Prev 2000;9:1149-54

36 De Boer JG, Yang H, Holcroft J, Skov K. Chemoprotection against Nnitrosomethylbenzylamine-induced mutation in the rat esophagus. Nutr Cancer 2004;50:168-73.

37 Yang CS, Lambert JD, Ju J, Lu G, Sang S. Tea and cancer prevention: molecular mechanisms and human relevance. Toxicol Appl Pharmacol 2007:224:265-73.

38 Shukla Y. Tea and cancer chemoprevention: a comprehensive review. Asian Pac J Cancer Prev 2007;8:155-66.

39 Sewram V, De Stefani E, Brennan P, Boffetta P. Mate consumption and the risk of squamous cell esophageal cancer in Uruguay. Cancer Epidemiol Biomarkers Prev 2003;12:508-13.

40 Fagundes RB, Abnet CC, Strickland PT, Kamangar F, Roth M], Taylor PR, et al. Higher urine 1-hydroxy pyrene glucuronide (1-OHPG) is associated with tobacco smoke exposure and drinking mate in healthy subjects from Rio Grande do Sul, Brazil. BMC Cancer 2006:6:139.

41 Kamangar F, Schantz MM, Abnet CC, Fagundes RB, Dawsey SM. High levels of carcinogenic polycyclic aromatic hydrocarbons in mate drinks. Cancer Epidemiol Biomarkers Prev 2008;17:1262-8.

42 Edwards FC, Edwards $\mathrm{H}$. Tea drinking and gastritis. Lancet 1956;271:543-5.

43 Pearson RC, McCloy RF. Preference for hot drinks is associated with peptic disease. Gut 1989;30:1201-5.

44 Victora CG, Munoz N, Horta BL, Ramos EO. Patterns of mate drinking in a Brazilian city. Cancer Res 1990;50:7112-5.

45 Graham DY, Abou-Sleiman J, El Zimaity HM, Badr A, Graham DP, Malaty HM. Helicobacter pylori infection, gastritis, and the temperature of choice for hot drinks. Helicobacter 1996;1:172-4.

46 McLaughlin JK, Gridley G, Block G, Winn DM, Preston-Martin S, Schoenberg JB, et al. Dietary factors in oral and pharyngeal cancer. Natl Cancer Inst 1988;80:1237-43.

47 Gangane N, Chawla S, Anshu, Gupta SS, Sharma SM. Reassessment of risk factors for oral cancer. Asian Pac J Cancer Prev 2007;8:243-8.

48 World Cancer Research Fund and American Institute for Cancer Research. Food, nutrition, physical activity, and the prevention of cancer: a global perspective. Washington, DC: AICR, 2007.

Accepted: 18 December 2008 